\title{
Thyroid Carcinoma Secondary to Radiation Cloud Exposure from the Chernobyl Incident of 1986: A Case Study
}

\author{
Andrew L. Atkinson ${ }^{\mathrm{a}} \quad$ Andrew Rosenthal ${ }^{\mathrm{b}}$ \\ aSaba University School of Medicine, Netherlands Antilles, and ${ }^{\text {b Department }}$ \\ Trauma Surgery, Memorial Regional Hospital, Hollywood, Fla., USA
}

\section{Key Words}

Chernobyl · Radiation · Thyroid · Papillary carcinoma

\begin{abstract}
The Chernobyl accident of 1986 exposed most if not all of Europe to a blanket of radiation, creating a melting pot of human exposure sequelae that is still showing up in our medical clinics today. In our particular clinic, a young woman of 29 years presented with most of her extended family in attendance. The young woman was born and raised in northern Italy until the age of seven when she left and immigrated to the United States leaving most of her family behind. Shortly after the Chernobyl accident, 5 members of her family, all woman including her own mother, were diagnosed with papillary thyroid carcinoma. Twenty-two years later, this same young woman came into the clinic with papillary thyroid carcinoma, making her the sixth member of her family. This case report illustrates the patient's history with her radiation exposure while talking in depth about the source, Chernobyl.
\end{abstract}

\section{Introduction}

On April 26th, 1986, in the little town of Chernobyl, Ukraine, the worst nuclear accident known to man engulfed most of Europe in a blanket of high-dose radiation. More than 20 years later, we are still coming across patients who are presenting with radiation exposure-related pathology from their early childhood in Western Europe.

We report a case of a 29 -year-old, Italian-born individual who has a significant family history of papillary thyroid carcinoma. She was referred to the surgical clinic after an ultrasound revealed a multinodular goiter with irregular nodule margins suspicious of carcinoma. 


\begin{tabular}{|c|c|c|c|}
\hline $\begin{array}{l}\text { Case Reports in } \\
\text { Oincaly }\end{array}$ & $\begin{array}{l}\text { Case Rep Oncol 2010;3:83-87 } \\
\text { D0I: } 10.1159 / 000308358\end{array}$ & Published online: April 8, 2010 & $\begin{array}{l}\text { @ } 2010 \text { S. Karger AG, Basel } \\
\text { ISSN 1662-6575 } \\
\text { www.karger.com/cro }\end{array}$ \\
\hline
\end{tabular}

\section{Case Report}

A 29-year-old, Italian-born American female presented to the outpatient surgery clinic, being referred by her endocrinologist for suspicious findings on thyroid ultrasound. The ultrasound revealed a generalized multi-nodular cystic thyroid with a massive left lobe mass measuring approximately $5.92 \times$ $4.59 \times 4.78 \mathrm{~cm}$.

The patient was born in Trento, Italy on March 9th, 1980, and lived there until she immigrated to the United States in 1987. In 1986, the worst documented nuclear accident in history happened at a power plant in Chernobyl, Ukraine, roughly 950 miles west of where the patient was born and living at the time. In the aftereffects of this accident, multiple large radiation clouds formed that spread throughout Eastern and Western Europe not excluding Northern Italy. Individuals in those areas were told not to consume vegetables from the ground, drink cow's milk, or consume any sort of meat from animals indigenous to the area. The radiation clouds were constantly fed by a graphite fire at ground zero for a period of roughly 10 days. Depending on wind and weather patterns, there were many 'hot spots' throughout Europe where radiation levels were in upwards of 100 times the levels of normal background radiation (

When taking the family history of this particular patient, she revealed that she had 4 aunts on her paternal side who had been diagnosed and treated surgically for papillary thyroid cancer. The aunts were $37,42,44$, and 50 years of age at the time of diagnosis and all lived in the same city, Trento, Italy. Two of the 4 aunts went for total thyroidectomies, while one had a right thyroid lobectomy and the fourth had a left thyroid lobectomy with isthmusectomy. The 2 patients who had had only partial removal of the thyroid had to return to the operation room approximately 12 months later to have the remaining lobes of the thyroid removed because of reoccurence of papillary carcinoma. All 4 of our patient's aunts went through radioactive iodine treatment after their surgeries. The patient's mother had also been diagnosed and treated surgically for papillary thyroid cancer. Incidentally, all of these diagnoses occurred after the Chernobyl accident of 1986.

The patient's past medical history was remarkable for an unspecified thalassemia trait. She denied any past problems with episodes of long sustained bleeding or ever having had to receive a blood transfusion. She denied use of alcohol, but did smoke 3-4 cigarettes daily.

On review of the systems, the patient had a history of progressive dysphagia for solids for the past 6 months, and shortness of breath when lying in the supine position that had started within the last 3 months. On physical examination, the patient had a hard, small, nontender goiter. The rest of the physical examination was unremarkable. Lab values showed that her thyroid stimulating hormone level was 1.03 . The patient clinically had a functioning euthyroid. We then ordered an iodine uptake test, which revealed a 'cold' nodule in the left lower pole of the left lobe corresponding with the location of the solid mass found on ultrasound. A decision was made to perform a total thyroidectomy, based on the family history and findings on ultrasound and iodine uptake testing.

The patient was taken to the operating room. A curvilinear incision was made about two fingerbreadths above the sternal notch, corresponding with a natural skin crease. Superior and inferior platysmal flaps were developed, and a self-retaining thyroid retractor was placed. The strap muscles were separated at the midline to expose a large multinodular thyroid. At this point, the surgical team started to mobilize the right side, beginning laterally and working our way medially. The right superior and inferior parathyroid glands were detected and preserved on their own vascular pedicles. The right recurrent laryngeal nerve took its course directly under the mid-thyroid pole and this required careful dissection to preserve the nerve. A harmonic scalpel was used to divide the superior and inferior thyroid arteries at the level of the thyroid capsule. Hemostasis was adequate. The pyramidal lobe was identified and mobilized before we turned our attention to the left side of the thyroid. The left side of the thyroid was managed in a similar fashion as the right side. We removed the gland en bloc, the specimen was sent to the pathologist. There was no significant lymphadenopathy witnessed during the procedure.

The pathology report came back stating that sections from the left lobe confirmed papillary carcinoma. The lesion was completely encapsulated and consisted of a single layer of epithelial cells on the outer edge. Psammoma bodies were observed as well as ground glass nuclei. The tumor was confined to the thyroid gland with no evidence of lymphovascular invasion. Small, scattered 2-3-mm foci of tumor could be seen throughout the left lobe; the isthmus and right lobe were unremarkable. Subsequently, the patient was started on radioactive iodine treatment after surgery. A study conducted by the American Thyroid Association in 2007 showed that $12 \%$ of patients with micropapillary cancer who received radioactive iodine treatment after surgery required a second treatment of radioactive iodine 11-60 months later because the cancer had come back. For those patients with less than $1 \mathrm{~mm}$ 


\begin{tabular}{|c|c|c|c|}
\hline $\begin{array}{l}\text { Case Reports in } \\
\text { Oningaty }\end{array}$ & $\begin{array}{l}\text { Case Rep Oncol 2010;3:83-87 } \\
\text { Dol: } 10.1159 / 000308358\end{array}$ & Published online: April 8, 2010 & \begin{tabular}{|l} 
@ 2010 S. Karger AG, Basel \\
ISSN 1662-6575 \\
www.karger.com/cro
\end{tabular} \\
\hline
\end{tabular}

thyroid cancer, $19 \%$ of those who received post-operative radioactive iodine treatment also required a second radioactive iodine treatment [1]. In short, follow-up with these patients months to years down the road is very important when dealing with papillary thyroid carcinoma.

\section{Discussion}

In areas of Europe that were affected by the Chernobyl radiation clouds, it has been estimated that more than $80 \%$ of thyroid dose came from internal exposure to $\mathrm{I}^{131}$ which in that case has a short half-life of 5-8 days. In 'hot spot' areas, thyroid doses in children under 7 years of age were among the highest, and ranged between $<0.05$ to $4 \mathrm{~Gy}$ with an average absorbed thyroid dose of $0.7 \mathrm{~Gy}$. In radiation exposures ranging from about 1 to 2 Gy, permanent effects, or mild radiation poisoning, begin. Most people experience mild nausea, sometimes accompanied by vomiting, which lasts for about a day. A feeling of general illness persists for a week or two. For levels of radiation more intense than this, consequences are more harmful. For every additional Gy past 1, the chance of death within 30 days increases by about $15 \%$, adding to the baseline mortality rate of $10 \%$. This means that about $25 \%$ of all people die within 30 days of exposure to $2 \mathrm{~Gy}$, around $40 \%$ of people die after exposure to $3 \mathrm{~Gy}$, and about $55 \%$ of people die after exposure to $4 \mathrm{~Gy}$. At $6 \mathrm{~Gy}$, the death rate is approximately 90 to $100 \%$. The primary causes of death are internal bleeding or immune system failure that rapidly gives way to lethal infection. Hair is lost, people are rendered sterile, bone marrow is destroyed, and while recovery is possible over years, in most cases damage is permanent [2].

There has been extensive documentation of thyroid cancer secondary to exposure of environmental radiation dating back to World War II when atomic bomb survivors were longitudinally studied in Japan after the bombs were dropped on Hiroshima and Nagasaki. A study conducted in 2003 by Misa Imaizumi, MD, of the Radiation Effects Research Foundation, revealed that out of the 4,091 atomic bomb survivors studied, $44.8 \%$ had thyroid pathology. Out of the $44.8 \%$ of the participants with some sort of thyroid disease, $28 \%$ had solid tumors of which over $35 \%$ were positive for malignant transformation [3]. Interestingly, the accident at Chernobyl was approximately 400 times more potent than the atomic bomb dropped on Hiroshima [4].

This patient presentation is a very rare finding in a hospital setting in the United States. Even though we have had our share of accidents in the past, i.e. the Three Mile Island accident of 1979, we normally do not deal with individuals who have been exposed to heavy amounts of radiation in their lifetime. It goes to show that an adequate family and social history is important in any examination with a new patient, especially when dealing with a gland like the thyroid. This particular patient did very well post-operatively and handled chemotherapy treatments with relative ease. She eventually returned to Italy a little over a year after her surgery, and she is being followed closely by an endocrinologist there.

\section{Consent}

Written informed consent was obtained from the patient to publish this case report. 
Fig. 1. 'Hot spots' 10 days after the explosion of Chernobyl. The radiation levels are measured in curies (Ci) per square kilometer $(1 \mathrm{Ci}=$ activity of $1 \mathrm{~g}$ of radium). An estimated $81 \mathrm{million} \mathrm{Ci}$ of radioactive cesium was released from Chernobyl. Illustration taken from [5].

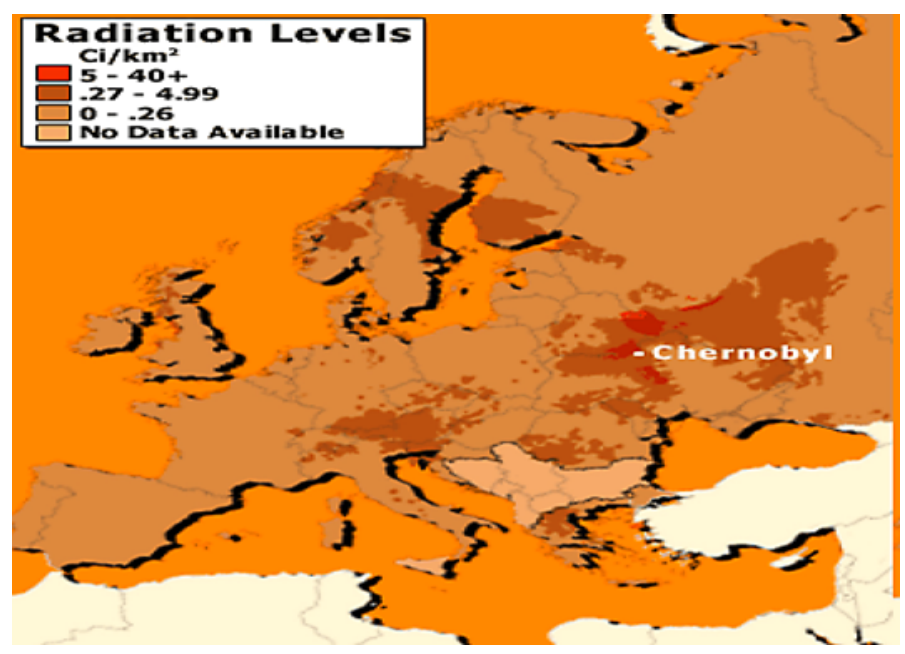




\section{References}

1 American Thyroid Association: Small papillary thyroid cancer is not without risk. Science Daily, 9 October 2007. http://www.sciencedaily.com /releases/2007/10/071005144830.htm (accessed February 24, 2010).

2 Agency for Toxic Substances and Disease Registry (ATSDR): Toxicological profile for ionizing radiation. Atlanta, GA: U.S. Department of Health and Human Services, Public Health Service, 1999.

-3 Imaizumi M: $45 \%$ of atomic bomb survivors in Japan have thyroid disease. JAMA 2006;295:1060-1062.

4 International Atomic Energy Agency, 2010. How does Chernobyl's effect measure up to the atomic bombs dropped on Hiroshima and Nagasaki? http://www.iaea.org/NewsCenter/Features/Chernobyl-15/cherno-faq.shtml (accessed March 1, 2010).

5 Plante B: Chernobyl, 22 years later. CBS News, 2008.

http://www.cbsnews.com/htdocs/nuclear_disasters/images/map_europe.gif (accessed March 1, 2010). 